\title{
Tissue Engineering in Urology- Progress and Prospects - A Review Article
}

\section{Joseph Philipraj S*, Prasanna Ram and Parthiban N \\ Department of Urology, MGMCRI- Sri Balaji Vidyapeeth University, India}

*Corresponding author: Joseph philipraj S, Department of Urology, MGMCRI- Sri

Balaji Vidyapeeth University, Pondicherry, India, Tel: 7094012857; Email: josephphilipraj@gmail.com

\section{Review Article \\ Volume 4 Issue 2}

Received Date: April 24, 2019

Published Date: May 14, 2019

DOI: 10.23880 /oajun-16000164

\section{Abstract}

Regenerative medicine is a new branch of medicine based on tissue engineering technology. This field of science has many things to offer in reconstructive urology where native organ is non-functional, and no substitute is available. Despite the initial promising results, it has not become a reality in the true sense. There are numerous obstacles that are slowing down the process of regenerative medicine. The progress shown in stem cell biotechnology and material science provides new vistas to translate experimental methods clinical reality. Tissue engineering encompasses a multidisciplinary approach with the main aim of development of biological substitutes designed to restore and maintain normal function in diseased or injured organs. This review is done to ascertain its current status and the progress that has been made in regenerative medicine in the reconstruction of various Genito-urinary organs.

Keywords: Regenerative Medicine; Tissue Engineering Technology; Reconstructive Urology; Stem Cell Biotechnology; Genito-Urinary Organs

Abbreviations: ECM: Extracellular Matrix; SIS: SmallIntestinal Submucosa, PGA: Polyglycolic Acid, ESRD: End Stage Renal Disease.

\section{Introduction}

Cancer, congenital anomalies, infection, trauma, inflammation, iatrogenic injuries, and/or other conditions of the GU system can lead to a complete loss of function or even organ damage. In the event of organ damage, the need for eventual reconstruction or replacement is indicated. In today's scenario, native non-urologic tissues (skin, gastrointestinal segments, or mucosa from different parts of the body), homologous tissues from a donor like cadaver fascia or cadaver or living donor kidney, heterologous substances like bovine collagen, or artificial materials (silicone, polyurethane, or polytetrafluoroethylene) are used for the reconstruction. The use of these materials can lead to a number of complications after reconstruction, as the implanted tissue may be rejected or because of the inherent different functional parameters that cause a mismatch in the system. So, the replacement of the damaged tissues with functionally similar ones should improve the results of the reconstruction. This is fast becoming a reality due to the rapid advances in tissue engineering. Recent advances in urology with regards to tissue bio engineering with significant possibilities for implementation pertaining to reconstructive surgery, has revolutionized the way we approach these scenarios. 
Reconstructive urology involves a variety of posttraumatic procedures, which are both cosmetic and functional, for injuries to the genitourinary tract. The use of bowel segments in bladder augmentation and neobladder formation is both extensive and well known. These procedures are not only technically demanding but can also be hindered by the limited availability of local tissue that is usable. The possibility of harvesting tissues from other sites in the body has been experimented with, however the potential for new complications at distant body sites is a major [1].

Tissue engineering is defined as - "an interdisciplinary field that applies the principles of engineering and the life sciences toward the development of biological substitutes that restore, maintain or improve tissue function" [2]. Today, tissue engineering techniques are being used for every type of organ and every type of tissue with the goal being to restore the function of a tissue and/or organ by delivering living elements that become integrated into the patient [3]. The goal of tissue engineering is the development and the successful implantation of functional biologic substitutes into organ thereby restoring its function. It usually involves a matrix of some kind, used as a platform on which cells may be introduced. These cells are usually of two types- the autologous type or pluripotent precursor cell types.

\section{History of Tissue Engineering in Urology}

First experimental studies on urinary tract reconstruction were carried out by Tizzoni and Poggi in 1888. Neuhof in 1917 presented human urinary bladder augmentation with fascia [4]. In the fifties Bricker, Kock and other presented different kinds of urinary diversion techniques. Studer and coworkers in 1985 showed orthotopic urinary bladder constructed from ileum, which became the most popular orthotopic bladder $[5,6]$. The orthotopic bladder and ileal conduit are both the most popular diversion techniques, but there are many complications related to bowel segments used for urinary diversion. In 1991, Narem and Vacanti defined tissue engineering, which is a discipline based on biomaterial science and knowledge on cell culture to prepare in vitro living grafts and constructs that, can be used for tissue regeneration or replacement [7]. The history of tissue engineering started over one hundred years ago. Experimental works of Harrison, Carrel, and Rous showed the possibility to culture cells outside the body [8-10]. Tissue engineering techniques were developed and introduced into the clinic by Gallico, Ricordi, Brittberg, and many prominent doctors and scientists [11-14].

\section{Tissue Engineering Strategies for Urogenital Repair}

Tissue engineering uses the principles of cell transplantation, material science, and biomedical engineering to make and use biologic substitutes that can restore and maintain normal or near-normal function of the damaged or defunct tissues and organs. Tissue engineering involves injection of functional cells into a nonfunctional site to stimulate regeneration. It also involves the use of natural or synthetic matrices, which are called scaffolds, which encourages the body's natural ability to repair itself and assist in the path of orientation and direction of new tissue growth. Most often, tissue engineering uses a combination of these techniques i.e., matrices seeded with cells can be implanted into the body to promote growth of functional tissue [15].

\section{Role of Cells in Urogenital Tissue Engineering}

Often, when cells are used for tissue engineering, the donor tissue is split into individual cells, which are then directly implanted into the host, expanded in culture media, mounted on a support matrix, and finally reimplanted after expansion. The implanted tissue can be autologous, allogeneic, or heterologous. This approach is ideal as it allows the lost tissue function to be restored in toto, with the complications being limited.

A common cause of concern is the source of the cells for regeneration. The concept of designing engineered tissue constructs which involves the obtaining of normal or near-normal cells from the organ that is to be replaced and expanding these cells in vitro so that sufficient quantities are made available for the technique of implantation chosen. Of course, this will cause concern, in a manner where in certain cases, there may not be enough normal cells present in the diseased organ to begin this expansion process. It is accepted that genetically normal progenitor cells, which are the precursors for new cell formation and are present even in diseased tissue, are rewired to give rise to normal tissue, regardless of the fact if whether they reside in the normal or the diseased tissues. Therefore, the stem cell hypothesis, and its role in normal tissue regeneration, remains a fertile area of ongoing investigation [16-21].

Human embryonic stem cells have the ability of differentiating into cells from all three embryonic germ layers, thus proving to have true pluripotency [22]. Ectodermal structures such as skin and neurons, mesodermal structures, such as blood, cardiac cells, and 
cartilage $[23,24]$ and endodermal structures, such as pancreatic cells [25] have all been formed in vitro. The use of human embryonic stem cells requires fetal demise and is a highly debated ethical and political dilemma [26]. Due to obvious reasons, research is ongoing for other more ethically neutral sources of stem cells for use in the study of regenerative medicine.

Fetal cells have been in the clinical scenario for the last decade. Umbilical cord blood has stem-cell potential and has been used both in the treatment of hematological disorders [27] and as a source of mesenchymal stem cells. The fetal kidney, the metanephric mesenchyme to be specific, is a potential source of these stem cells as well [28]. Although the clinal use of hematopoietic cells has been around, there are still ethical hurdles regarding the actual transplantation of fetal tissue [29]. Autologous amniotic fluid stem cells are also under investigation as another source of ethically neutral pluripotent progenitor cells [30].

Adult stem cells have the advantage of avoiding some of the ethical issues associated with embryonic cells, and, unlike embryonic cells, they do not transdifferentiate into a malignant phenotype; thus, there is a reduced risk for teratoma formation should the cells is implanted in vivo. Adult stem cells are limited for clinical use, however, because expansion to the large quantities needed for tissue engineering is difficult.

\section{Therapeutic Cloning}

Nuclear cloning, which has also been called nuclear transplantation and nuclear transfer, by definition involves the introduction of a nucleus from a donor cell into an enucleated oocyte to create an embryo with a genetic makeup identical to that of the donor. In literature two types of nuclear cloning have been described, namely reproductive cloning and therapeutic cloning. As cloning is banned in most countries for use in humans, reproductive cloning usually generates an embryo that contains the identical genetic material as its cell source to produce an offspring that are genetically identical to the donor, the opposite of which is therapeutic cloning, which is used to generate early-stage embryos that are used in vitro. They are explanted in culture to produce embryonic stem cells that are genetically identical to the source. These autologous stem cells can become almost any type of cell in the adult body, and hence can be used in tissue and organ replacement applications [31]. A particularly useful scenario for these cells would be in the treatment of End Stage renal disease [ESRD], where there is limited availability of immune-compatible tissue transplants.

\section{Biomaterials for Genitourinary Tissue Construction}

Biomaterials in genitourinary tissue engineering act as an artificial extracellular matrix (ECM) and are used to replace biologic and mechanical functions of native ECM found in tissues in the body. Biomaterials facilitate the localization and delivery of cells or bioactive factors like cell adhesion peptides and growth factors, to desired sites in the body and define a 3D space for the formation of new tissues with a proper structure. They also serve as a framework for the development of new tissues with appropriate function [32,33]. Direct injection of cell suspensions without such matrices has been used in some cases, but without this scaffold function, controlling the localization of transplanted cells appears difficult [34].

The ideal biomaterial should be biocompatible, increase cellular interaction and development of tissue, and have the similar mechanical and physical properties found in the tissue to be generated. Generally, three classes of biomaterials have been used for the engineering of genitourinary tissues:

- Naturally derived materials, such as collagen and alginate

- Acellular tissue matrices, such as bladder submucosa and small-intestinal submucosa (SIS); and

- Synthetic polymers, such as polyglycolic acid (PGA), polylactic acid, and polylactic-co-glycolic acid.

Although synthetic polymers can be produced reproducibly on a large scale with controlled properties of strength, degradation rate and microstructure, the naturally derived materials and acellular tissue matrices have the potential advantage of biologic recognition, which can lessen host-versus-graft reactions.

\section{Vascularization of Engineered Tissue}

Limitations of nutrient and gas exchange currently restrict tissue-engineered implants to a volume of nearly $3 \mathrm{~mm}$ [35]. Therefore, to realize the goals of engineering large complex tissues and organs, vascularization of the regenerating cells is crucial. Three approaches have so far been used to promote the vascularization of the bioengineered tissue.

- Incorporation of angiogenic factors in the bioengineered tissue has been used to draw in host capillaries and to enhance neovascularization of the implanted tissue. 
- Seeding endothelial cells with other cell types in the bioengineered tissue.

- Pre-vascularization of the matrix before cell seeding has been attempted.

There are many obstacles to overcome prior to large scale production of tissue-engineered solid organs, but recent developments in angiogenesis research may provide important knowledge and the required materials to accomplish this goal. Efforts are currently underway to engineer tissue from every cell type of the GU system that a biological substitute for use in reconstructive surgical procedures may be developed. Artificial kidney, ureter, bladder, urethra, and skin, once successfully engineered, could be used in the maintenance, restoration, and improvement of tissue function, all without utilizing tissue from a distant site or separate organ system. Tissue bioengineering may provide a novel source of autologous biocompatible tissues for use in reconstructive urologic procedures.

\section{Kidney}

Renal failure patients invariably end up in hemodialysis and transplantation. These methods have proved indispensable to the management of patients with end-stage renal disease. Renal transplantation is the gold standard of therapy, with dialysis as a necessity for donor kidney availability. Both carry certain Morbidities unique to each, ranging from effects on the lifestyle, problematic vascular access, donor shortage, graft rejection, and costly interventions [36].

More advanced forms of hemodialysis are the renal assist device and the Bioartificial kidneys. While the former is still subject to the morbidity of being an externalized dialysis unit with the need for vascular access and the latter still needs a portable transplantable unit for ease of use. Tissue engineering provides a cuttingedge alternative to artificial approximation of renal function. Renal bioengineering is especially challenging given the multiple functions of the kidney and the intricacy of its structure. Cell transplantation and kidneycell expansion has been proposed as a method of augmenting or supplementing renal-cell function in impaired kidneys. A possible strategy involves the extraction (via biopsy) of renal cells from an affected kidney, growth of these cells in culture, seeding of these cells onto a scaffold, and finally implantation of the scaffold back into the original patient.

Atala, et al. [37] showed in vivo renal-cell growth and nephron organization after extracorporeal attachment to such a biodegradable polymer scaffold. It was later shown that even single cells could redevelop into tubular structures once seeded [38]. More recently, threedimensional culture systems that promote adhesion of expanded cells to one another as opposed to the culture dish have been utilized. This allows for generation of more three-dimensional tissue units [39].

Expanded primary renal cells, when placed in such a system, began to develop into structures that looked like tubules and glomeruli and stained positively for TammHorsfall protein, which is normally expressed in the thick ascending limb of the loop of Henle, as well as the distal convoluted tubules [40]. Extensive research has gone into the nature of the scaffold. An acellular collagen-based kidney matrix has proven to be a good frame to which renal cells can adhere and develop into tubules [41]. This is a naturally derived lattice that has potential to be the basis for renal augments in the future. Modifications have been made to the scaffold to further enhance survival of engineered tissue, such as incorporation of calciumperoxide-based oxygen-generating particles [42]. Cellbased approaches have shown promise, both in vitro and in vivo, but the clinical application of this technology is still relatively far away.

\section{Ex Vivo Functioning Renal Units}

An attempt to assess the viability and physiologic functionality, a synthetic hemofiltration device that contained tissue-engineered porcine renal tubules were incorporated into an extracorporeal perfusion circuit, demonstrated the feasibility of an extracorporeal assist device that is reinforced by the use of proximal tubular cells [43]. Using similar techniques, a tissue-engineered bioartificial kidney using a conventional hemofiltration cartridge in addition to a renal tubule assist device that has human renal proximal tubule cells was used in patients with acute renal failure in the ICU. The initial clinical experience with this bioartificial kidney suggests that renal tubule cell therapy may provide a dynamic and individualized treatment program as assessed by acute physiologic and biochemical indices.

\section{In Vivo Functioning Renal Units}

Another approach to improve renal function by augmentation of renal tissue with kidney cells expanded in vitro and used for subsequent autologous transplantation. Most recently, an attempt was made to reconstitute renal epithelial cells for the generation of functional nephron units. Renal cells were harvested, expanded in culture \& were seeded onto a tubular device constructed from a polycarbonate membrane, which was connected at one end to a Silastic catheter that terminated 


\section{Open Access Journal of Urology \& Nephrology}

in a reservoir. Further studies have shown the formation of renal structures in cows using nuclear transfer techniques [44].

\section{Ureter}

Non-seeded acellular matrix grafts have been implanted in rats, with regeneration of ureteral wall components, but subsequent efforts to use such grafts in tubularized ureteral replacement were unsuccessful. Cellseeded synthetic scaffolds, however, have shown promise. Cells were expanded in vitro and applied to lattices of tubular polyglycolic acid. After subcutaneous implantation, in vivo layering was noted, with luminal and muscle layers. In a more recent study, non-seeded acellular collagen matrices were tubularized and used to replace $3-\mathrm{cm}$ segments of canine ureters but was not able to replace the segment of the ureter successfully [45].

\section{Bladder}

Currently, gastrointestinal segments are commonly used for bladder replacement or repair as they absorb solutes that urinary tissue excretes, however, not free of complications, such as infection, metabolic disturbances, urolithiasis, perforation, increased mucus production, and malignancy $[46,47]$. As a result numerous investigators have attempted alternative reconstructive procedures for bladder replacement or repair. The use of tissue expanders, seromuscular grafts, matrices used tissue regeneration, and tissue engineering with cell transplantation has been studied.

The concept of seeding a scaffold with cells is that the matrix serves as the lattice on which the cells can grow and differentiate; as this occurs, the scaffold itself degrades until all that remains is engineered bladder tissue. The important criteria for such a matrix are

- that it is acellular, so that the bladder cells are the only true cells in the graft;

- that it will degrade to leave only graft behind; and

- that it is immunologically inert and will not provoke a host response against it.

Cell-seeded bladder matrices were first used in dogs. It was seen that tissue-engineered bladder specimens showed a normal capacity to retain urine, normal compliance, and normal histologic organization [48]. Ongoing clinical trials further investigate the utilization of tissue-engineered bladders in human subjects. These studies suggest that tissue-engineered bladders may be a viable option not only for patients of the future but also for patients of the present day.

\section{Urethra}

The urethra can be compromised by congenital abnormalities, but it is most often the acquired maladies that necessitate urethral surgery. Posttraumatic defects can often not be repaired primarily and may require harvesting of tissue from distant body sites for successful reconstruction. The use of local skin flaps has been described, as have graft harvests of bladder or buccal mucosa [49], but these are still subject to complications. Animal studies replacing urethral tissue with segments of acellular collagen-based matrix graft in an onlay fashion have been described [50]. This approach was subsequently applied in human subjects with hypospadias or urethra stricture disease as the impetus for reconstructive surgery. In addition, anastomosing the acellular matrix in an onlay fashion, has the advantage of that it does not have to be implanted with host cells and can be packaged and distributed for immediate "off-theshelf" use, obviating the need for graft harvest and excess morbidity.

Acellular matrix grafts are effective for shorter length strictures less than $0.5 \mathrm{~cm}$ long [51]. Acellular matrices are only able to successfully replace urethra if anastomosed in an onlay fashion. Attempts at tubularized repair using acellular matrices proved unsuccessful, with development of recurrent strictures and contracture of the grafts [52]. If tubularized segments of urethra are needed, cell-seeded matrices tend toward more promising results [53]. As shown in animal studies, the tubularized matrices, when seeded with autologous bladder epithelial and smooth muscle cells, develop into stricture less urethras of normal caliber, whereas acellular matrices uniformly result in collapsed urethral sections with stricture development.

\section{Penis}

The application of reconstructive surgery in the case of the penis is largely related to erectile dysfunction where corporal tissue has lost its erectile function, and the main conceptual goals remain the same: either augment existing corporal function or introduce a substitute for it. Tissue engineering attempts to side step potential complications of medical and surgical therapy to ED by utilizing implant that is either immunologically inert or of autologous origin.

Cell-seeding techniques have been attempted using culture-expanded corporal smooth muscle cells applied to biodegradable polyglycolic acid polymers [54]. Acellular nerve grafts to augment more rapid return of erectile function of transected cavernous nerves at the time of 
deep pelvic surgeries, most notably radical prostatectomy. A substitutive effect analogous to a semirigid prosthesis is novel formation of cartilaginous rods by seeding chondrocytes on cylindrical scaffolds.

\section{Testes}

The main function of the testis is the production of androgens, which in turn have many effects on male development, muscle, bone, and sexual function. Testicular dysfunction can arise in various congenital or acquired conditions thus rendering functionally anorchic, lifelong androgen requirement therapy may be required to maintain physiological levels of testosterone and avoid adverse impacts on growth and sexuality. One basic approach toward restoration of testicular function in males is the transplantation of Leydig cells (interstitial cells) from a donor into the anorchic male but is limited by rejection of the foreign cells by the host's immune system. Currently, studies are focusing on immune protection of the transplanted cells via encapsulation in a protective semipermeable membrane that is biologically compatible with the recipient [55].

Another approach involves the creation of a testicular prosthesis that is capable of eluting testosterone. Testicular- shaped prostheses with a hollow center, made of tissue-engineered chondrocytes were created in a bioreactor and then filled with $100 \mu \mathrm{g}$ of testosterone enanthate and both maintained in culture and implanted into athymic mice [56]. Such prosthesis could have a role in patients who require both prostheses and chronic hormone supplementation; though such prosthesis would require periodic reinjections of a new testosterone load into the hollow center of the prosthesis, it could provide a more cosmetic option to injectable testosterone that decreased the frequency of injection needed.

\section{Female Genital Tissues}

Patients who have cloacal exstrophy and intersex disorders may not have sufficient uterine tissue present for future reproduction. Autologous rabbit uterine smooth muscle and epithelial cells are harvested and expanded in culture. These cells were seeded onto preconfigured uterine-shaped biodegradable polymer scaffolds, and these were used for subtotal uterine tissue replacement in the corresponding autologous animals. On retrieval 6 months after implantation, histologic, immunocytochemical, and Western blot analyses confirmed the presence of normal uterine tissue components. Biomechanical studies and organ bath studies were suggestive of the fact that the functional characteristics of these tissues were similar to those of normal uterine tissue. Breeding studies using these engineered uteri are currently being performed. Similarly, different pathologic conditions, that include congenital malformations and malignancies, can adversely affect normal vaginal development [57].

The primary goal of vaginal reconstruction is the approximation of anatomic normalcy and functional normalcy a secondary and largely unaddressed goal. Both the vaginal epithelial and smooth muscle cells of female rabbits were harvested, grown, and expanded in culture media. These cells were seeded onto biodegradable polymer scaffolds, and the cell-seeded constructs were then implanted into nude mice for up to 6 weeks. Immunocytochemical, histologic, and Western blot analyses were used and they confirmed the presence of vaginal tissue phenotypes. Electrical field stimulation studies in the tissue-engineered constructs showed similar functional properties to those of normal vaginal tissue. When these constructs were used for autologous total vaginal replacement, patent vaginal structures were noted in the tissue-engineered specimens, whereas the non-cell-seeded structures were noted to be stenotic [58].

It should be noted that this has significant impact in the management of transgendered patients, specifically male-to-female transsexuals. This patient population represents not only a shift in the indications for vaginal reconstruction but also an increase in the number of reconstructive procedures that are being performed today. Currently, ileal segments are often used in vaginoplasty, and laparoscopic approaches have been described with good functional results [59]. Bioengineered vaginal tissue could represent a significant advancement in the practice of vaginal reconstruction in this growing population, in that it can result in a neovagina composed of normal epithelium, while obviating the morbidity associate with graft harvest.

\section{Ovary}

Ovarian compromise can be the result of anything that limits the ability to produce oocytes capable of differentiation into viable offspring, be it polycystic ovarian syndrome, ovarian failure, or sterility. The role of tissue engineering in these situations is less focused on the generation of de novo oocytes; instead, methods to apply tissue-engineering technology to the preservation of existing immature oocytes. Granulosa cell-oocyte complexes incorporated into an alginate hydrogel culture system showed no degeneration and an intact zona pellucida after 10 days. Approximately $40 \%$ of the oocytes retrieved from in vitro growth were capable of progressing to meiosis II. These studies could provide 
breakthroughs in the preservation of oocytes of women who are at risk for losing ovarian function, be it through progressive cystic disease or impending chemotherapy. Further studies have focused on the incorporation of ligands to the alginate lattice that can affect the behavior and structure of the oocytes themselves.

\section{Injectable Therapies}

The urinary system is one governed by flow dynamics, where one-way flow of urine is essential for proper functioning of the system. Vesicoureteral reflux represents a malfunction in the valve-like nature of the ureter as it tunnels through the bladder wall. Urinary incontinence involves a deficiency in the resistance to outflow of urine from the bladder. Although fundamentally different disorders, both can be treated with injection of bulking agents to limit flow of urine in an undesirable fashion.

Ideal injectable agents are biocompatible and biodegradable. Recently, Deflux has shown good results at treating vesicoureteral reflux [60]. For cases of urinary incontinence, collagen remains a commonly used bulking agent [61]. Autologous chondrocytes have been expanded in tissue culture, and the resulting solution injected cystoscopically to correct vesicoureteral reflux in children 50 , and for treatment of stress incontinence due to intrinsic sphincter deficiency in adults.

More recently, attempts to inject the rhabdosphincter itself with myoblasts caused significant strengthening one year later, with attainment of continence. Tissue engineering of injectable agents for bulking purposes shows promising practical application, largely because such usage is not dependent on scaffolding and structuring the development of a complex organ. Such agents are by definition nonantigenic and thus avoid the potential for allergic or inflammatory reaction in humans. They additionally have the potential to maintain their volumes, avoiding the need for repeat injection as the agent degrades and incontinence returns.

In addition, injectable muscle-based gene therapy and tissue engineering were combined to improve detrusor function in a bladder injury model and may potentially be a novel treatment option for urinary incontinence [62]. Patients with testicular dysfunction requiring androgen replacement for somatic development. A system was designed in which Leydig cells were microencapsulated for controlled testosterone replacement. Purified Leydig cells were isolated and encapsulated in an alginate-polyL-lysine solution. These Leydig cells were injected into castrated animals, and serum testosterone was measured serially; the animals were able to maintain testosterone levels in the long term. These studies suggest that micro encapsulated Leydig cells may be able to replace or supplement testosterone in situations in which anorchia or testicular failure is present.

\section{Fetal Tissue Engineering}

The prenatal diagnosis of fetal abnormalities is now more common and more accurate. Improvements in prenatal diagnosis have led to demand for novel interventions designed to reverse potentially lifethreatening processes before birth. Once the diagnosis of pathologic condition is confirmed prenatally, a small tissue biopsy could then be obtained under ultrasound guidance. These biopsy materials could then be processed expanded in vitro. Using tissue engineering techniques, in vitro-reconstituted structures could then be readily available at the time of birth for reconstruction.

\section{Summary}

Tissue bioengineering may provide a means of restoration of lost function without the need for grafts and with much lower morbidity. Currently a lot of effort is being put into every type of tissue and organ in the GU system. Tissue engineering techniques require a cell culture facility designed for human application. Personnel who have mastered the techniques of cell harvest, culture, and expansion in addition to polymer design are needed for the successful use of this technology. Before these engineering techniques can be applied to humans, further studies need to be performed in many of the tissues described. Recent studies and developments are pointing in the direction of the clinical use of engineered urologic tissue. Research is focused on improving methods of cell culture and in vitro expansion of cell lines; improvement of polymers for use as nonantigenic, biodegradable scaffolds for growth and organization of these cells; and implantation of these seeded scaffolds to assess tissue differentiation in vivo.

\section{References}

1. Dasgupta P, Fitzpatrick JM, Kirby R, Gill IS (2010) (Eds.), New Technologies in Urology, pp: 147-153.

2. Langer R, Vacanti J (1993) Tissue engineering. Science 260: 920.

3. Vacanti J, Langer R (1999) Tissue engineering: the design and fabrication of living replacement devices for surgical reconstruction and transplantation. Lancet 345: S32-S34. 


\section{Open Access Journal of Urology \& Nephrology}

4. Neuhof H (1917) Some observation in spinal cord surgery. Ann Surg 65(4): 410-437.

5. Bricker EM (1956) Substitution for the urinary bladder by the use of isolated ileal segments. Surg Clin North Am 36(4): 1117-1130.

6. Studer UE, deKernion JB, Zimmern PE (1985) A model for a bladder replacement plasty by ileal reservoir-an experimental study in dogs. Urol Res 13(5): 243-247.

7. Cima LG, Vacanti JP, Vacanti C, Ingber D, Mooney D, et al. (1991) Tissue engineering by cell transplantation using degradable polymer substrates. J Biomech Eng 113(2): 143-151.

8. Harrison RG (1910) The outgrowth of the nerve fiber as a mode of protoplasmic movement. J Exp Zool 9(4): 787-846.

9. Carrel A (1912) On the permanent life of tissues outside of the organism. J Exp Med 15(5): 516-528.

10. Rous P, Jones FS (1916) A method for obtaining suspensions of living cells from the fixed tissues and for the plating out of individual cells. J Exp Med 23(4): 549-555.

11. Gallico GG, O'Connor NE, Compton CC, Kehinde O, Green H (1984) Permanent coverage of large burn wounds with autologous cultured human epithelium. N Engl J Med 311(7): 448-451.

12. Ricordi C, Alejandro R, Zeng Y, Tzakis A, Casavilla A, et al. (1991) Human Islet Isolation and Purification From Pediatric-Age Donors. Transplant Proc 23(1): 783-784.

13. Brittberg $\mathrm{M}$, Lindahl A, Nilsson $\mathrm{A}$, Ohlsson $\mathrm{C}$, Isaksson 0 , et al. (1994) Treatment of deep cartilage defects in the knee with autologous chondrocyte transplantation. N Engl J Med 331(14): 889-895.

14. Oberpenning F, Meng J, Yoo JJ, Atala A (1999) De novo reconstitution of a functional mammalian urinary bladder by tissue engineering. Nat Biotechnol 17(2): 149-155.

15. Atala A (2009) Regenerative Medicine and Tissue Engineering in Urology. Urol Clin N Am 36(2): 199209.

16. Atala A, Vacanti JP, Peters CA, Mandell J, Retik AB, et al. (1992) Formation of urothelial structures in vivo from dissociated cells attached to biodegradable polymer scaffolds in vitro. J Urol 148(2): 658-662.

17. Atala A, Cima LG, Kim W, Paige KT, Vacanti JP, et al. (1993) Injectable alginate seeded with chondrocytes as a potential treatment for vesicoureteral reflux. J Urol 150(2): 745-747.

18. Atala A, Freeman MR, Vacanti JP, Shepard J, Retik AB (1993) Implantation in vivo and retrieval of artificial structures consisting of rabbit and human urothelium and human bladder muscle. J Urol 150(2): 608-612.

19. Atala A, Kim W, Paige KT, Vacanti CA, Retik AB (1994) Endoscopic treatment of vesicoureteral reflux with a chondrocyte alginate suspension. J Urol 152(2 Pt 2): 641-643.

20. Atala A, Bauer SB, Soker S, Yoo JJ, Retik AB (2006) Tissue-engineered autologous bladders for patients needing cystoplasty. Lancet 367(9518): 1241-1246.

21. Atala A (2003) Tissue engineering, stem cells, and cloning for the regeneration of urologic organs. Clin Plast Surg 30(4): 649-667.

22. Reubinoff BE, Pera MF, Fong CY, Trounson A, Bongso A (2000) Embryonic stem cell lines from human blastocysts: somatic differentiation in vitro. Nat Biotechnol 18(4): 399-404.

23. Kaufman DS, Hanson ET, Lewis RL, Auerbach R, Thomson JA (2001) Hematopoietic colony-forming cells derived from human embryonic stem cells. Proc Natl Acad Sci USA 98(19): 10716-10721.

24. Kehat I, Kenyagin-Karsenti D, Snir M, Segev H, Amit M, et al. (2001) Human embryonic stem cells can differentiate into myocytes with structural and functional properties of cardiomyocytes. J Clin Invest 108(3): 407-414.

25. Assady S, Maor G, Amit M, Itskovitz-Eldor J, Skorecki $\mathrm{KL}$, et al. (2001) Insulin production by human embryonic stem cells. Diabetes 50(8): 1691-1697.

26. Annas GJ, Elias S (1989) The politics of transplantation of human fetal tissue. $\mathrm{N}$ Engl J Med 320 (16): 1079-1082.

27. Watt SM, Contreras M (2005) Stem cell medicine: umbilical cord blood and its stem cell potential. Semin Fetal Neonatal Med 10(3): 209-220. 
28. Al-Awqati Q, Oliver JA (2002) Stem cells in the kidney. Kidney Int 61(2): 387-395.

29. Abouna GM (2003) Ethical issues in organ and tissue transplantation. Exp Clin Transplant 1(2): 125-138.

30. Perin L, Sedrakyan S, Da Sacco S, De Filippo R (2008) Characterization of human amniotic fluid stem cells and their pluripotential capability. Methods Cell Biol 86: 85-99.

31. Hochedlinger K, Rideout WM, Kyba M, Daley GQ, Blelloch R, et al. (2004) Nuclear transplantation, embryonic stem cells and the potentialforcell therapy. Hematol J 5(3): 114-117.

32. Kim BS, Baez CE, Atala A (2000) Biomaterials for tissue engineering. World J Urol 18(1): 2-9.

33. Kim BS, Mooney DJ (1998) Development of biocompatible synthetic extracellular matrices for tissue engineering. Trends Biotechnol 16(5): 224230.

34. Ponder KP, Gupta S, Leland F, Darlington G, Finegold $\mathrm{M}$, et al. (1991) Mouse hepatocytes migrate to liver parenchyma and function indefinitely after intrasplenic transplantation. Proc Natl Acad Sci U S A 88(4): 1217-1221.

35. Folkman J, Hochberg M (1973) Self-regulation of growth in three dimensions. J Exp Med 138(4): 745753.

36. Atala A, Retik AB, Schlussel RN (1995) Renal cell growth in vivo after attachment to biodegradable polymer scaffolds. J Urol 153: 209A.

37. Fung L, Elenius K, Freeman MR, Donovan MJ, Atala A (1996) Reconstitution of EGFr-poor renal epithelial cells into tubular structures on biodegradable polymer scaffold. Pediatrics 98S: 631.

38. Furlow WL (1976) Surgical management of impotence using the inflatable penile prosthesis. Experience with 36 patients. Mayo Clin Proc 51(6): 325-328.

39. Joraku A, Stern KA, Atala A, Yoo JJ (2008) In vitro generation of three-dimensional renal structures. Methods 47(2): 129-133.

40. Amiel GE, Yoo JJ, Atala A (2000) Renal therapy using tissue-engineered constructs and gene delivery. World J Urol 18(1): 71-79.
41. Oh SH, Ward CL, Atala A, Yoo JJ, Harrison BS (2008) Oxygen generating scaffolds for enhancing engineered tissue survival. Biomaterials 30(5): 752762 .

42. Humes HD, Buffington DA, MacKay SM, Funke AJ, Weitzel WF (1999) Replacement of renal function in uremic animals with a tissue-engineered kidney. Nat Biotechnol 17(5): 451-455.

43. Lanza RP, Chung HY, Yoo JJ, Wettstein PJ, Blackwell C, et al. (2002) Generation of histo compatible tissues using nuclear transplantation. Nat Biotechnol 20: 689-696.

44. Osman Y, Shokeir A, Gabr M, El-Tabey N, Mohsen T, et al. (2004) Canine ureteral replacement with long acellular matrix tube: is it clinically applicable?. J Urol 172(3): 1151-1154.

45. Kaefer M, Hendren WH, Bauer SB, Goldenblatt P, Peters CA, et al. (1998) Reservoircalculi: a comparison of reservoirs constructed from stomach and other enteric segments. J Urol 160(6 Pt 1): 21872190.

46. Kaefer M, Tobin MS, Hendren WH, Bauer SB, Peters CA, et al. (1997) Continent urinary diversion: the Children's Hospital experience. J Urol 157(4): 13941399.

47. Hendren WH, Reda EF (1986) Bladder mucosa graft for construction of male urethra. J Pediatr Surg 21(3): 189-192.

48. Chen F, Yoo JJ, Atala A (1999) Acellular collagen matrix as a possible "off the shelf" biomaterial for urethral repair. Urology 54(3): 407-410.

49. Dorin RP, Pohl HG, De Filippo RE, Yoo JJ, Atala A (2008) Tubularized urethral replacement with unseeded matrices: what is the maximum distance for normal tissue regeneration?. World J Urol 26(4): 323326.

50. le Roux PJ (2005) Endoscopic urethroplasty with unseeded small intestinal submucosa collagen matrix grafts: a pilot study. J Urol 173(1): 140-143.

51. De Filippo RE, Yoo JJ, Atala A (2002) Urethral replacement using cell seeded tubularized collagen matrices. J Urol 168(4): 1789-1792.

52. Park HJ, Yoo JJ, Kershen RT, Moreland R, Atala A (1999) Reconstitution of human corporal smooth 
muscle and endothelial cells in vivo. J Urol 162(3): 1106-1109.

53. Chang TM (1993) Bioencapsulation in biotechnology. Biomater Artif Cells Immobil Biotechnol 21(3): 291297.

54. Raya-Rivera AM, Baez C, Atala A, Yoo JJ (2008) Tissue engineered testicular prostheses with prolonged testosterone release. World J Urol 26(4): 351-358.

55. De Filippo RE, Yoo JJ, Atala A (2003) Engineering of vaginal tissue in vivo. Tissue Eng 9(2): 301-306.

56. Liguori G, Trombetta C, Bucci S, Salamè L, Bortul M, et al. (2005) Laparoscopic mobilization of neovagina to assist secondary ileal vaginoplasty in male-to-female transsexuals. Urology 66(2): 293-298.

57. Stenberg A, Läckgren G (1995) A new bioimplant for the endoscopic treatment of vesicoureteral reflux: experimental and short-term clinical results. J Urol 154(2 Pt 2): 800-803.

58. Monga AK, Robinson D, Stanton SL (1995) Periurethral collagen injections for genuine stress incontinence: a 2-year follow-up. Br J Urol 76(2): 156160.

59. Diamond DA, Caldamone AA (1999) Endoscopic correction of vesicoureteral reflux in children using autologous chondrocytes: pre -liminary results. J Urol 162(3): 1185-1188.

60. Bent AE, Tutrone RT, McLennan MT, Lloyd LK, Kennelly MJ, et al. (2001) Treatment of intrinsic sphincter deficiency using autologous ear chondrocytes as a bulking agent. Neurourol Urodyn 20(2): 157-165.

61. Huard J, Yokoyama T, Pruchnic R, Qu Z, Li Y, et al. (2002) Muscle-derived cell-mediated ex vivo gene therapy for urological dysfunction. Gene Ther 9(23): 1617-1626.

62. Machluf M, Orsola A, Boorjian S, Kershen R, Atala A (2003) Micro en-capsulation of Leydig cells: a system for testosterone supplementation. Endocrinology 144(11): 4975-4979. 